\title{
Analisis Potensi dan Pemanfaatan Sumberdaya Ikan (SDI) Yang Didaratkan di Pelabuhan Perikanan Teluk Awang
}

\author{
Analysis Of Potential And Utilization Of Fish Resources (SDI) That Were \\ Landed at The Fishing Port Of Teluk Awang
}

\author{
Sadikin Amir*, Sitti Hilyana, Saptono Waspodo, Soraya Gigentika, Edwin Jefri \\ Program Studi Ilmu Kelautan, Fakultas Pertanian, Universitas Mataram \\ *Corresponding Author Email: sadikinamir@gmail.com
}

Manuscript received: 08-12-2020. Accepted: 26-10-2021

\begin{abstract}
ABSTRAK
Pelabuhan Perikanan (PP) Teluk Awang berada di Desa Mertak, Kabupaten Lombok Tengah berpotensi untuk berkembang sebagai pusat pertumbuhan ekonomi dengan basis usaha perikanan. Memiliki letak geografis yang baik karena terlindung dari gelombang yang datang dari Samudera Hindia. Saat ini Pemerintah Pusat, Pemerintah Provinsi Nusa Tenggara Barat dan Pemerintah Kabupaten Lombok Tengah bersama-sama mengembangkan Teluk Awang menjadi sentra usaha perikanan dengan membangun pelabuhan perikanan yang dapat menampung kapal-kapal perikanan beroperasi di WPPNRI 573 dan 713. Penelitian ini akan melihat sumberdaya ikan (SDI) di PP Teluk Awang menggunakan metode Participatory Actiont Riset (PAR) yang melibatkan secara aktif semua pihak-pihak yang relevan. Hasil penelitan menunjukkan bahwa SDI yang di daratkan di PP Teluk Awang selama tahun 2018-2020 sebanyak $3.559 .483 \mathrm{~kg}$ masih didominasi oleh ikan pelagis dan demersal, seperti ikan Cakalang (62,67\%), Layang (10,77\%), Tongkol (8,29\%), Lemadang $(6,34 \%)$, Tuna $(5,42 \%)$, Baby Tuna $(3,88 \%)$, Marlin $(1,48 \%)$ dan Ikan lainya(1,15\%).Sedangkan jumlah armada kapal yang terdata sebanyak 27 unit dengan ukuran 8-25 Gross Tonnage (GT). Hasil penelitian ini diharapkan dapat menjadi rekomendasi terkait kebijakan dalam pengelolaan potensi SDI yang didaratkan di PP Teluk Awang dengan konsep perikanan berkelanjutan.
\end{abstract}

Kata kunci: sumberdaya; ikan; pelabuhan; perikanan

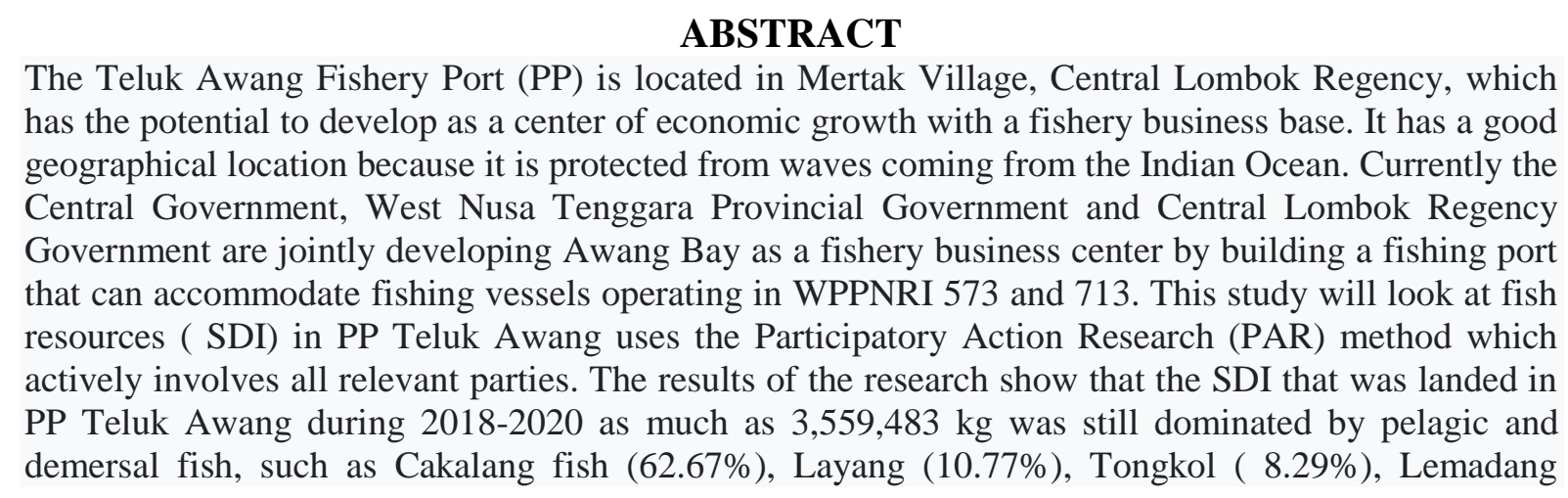


(6.34\%), Tuna (5.42\%), Baby Tuna (3.88\%), Marlin (1.48\%) and other fish (1.15\%). The recorded fleet of ships is 27 units with a size of $8-25$ Gross Tonnage (GT). The results of this study are expected to be a recommendation related to policies in managing the potential of SDI landed in PP Teluk Awang with the concept of sustainable fisheries.

Keywords: fish; resources, fishing; port

\section{PENDAHULUAN}

Pelabuhan Perikanan (PP) Teluk Awang berada di Dusun Awang, Desa Mertak, Kabupaten Lombok Tengah memiliki kemampuan untuk berkembang sebagai pusat pertumbuhan ekonomi dalam bidang usaha perikanan di Nusa Tenggara Barat maupun Indonesia. Hal ini dikarenakan pelabuhan berada di lokasi pemukiman nelayan yang sejak turun temurun masyarakatnya berprofesi sebagai nelayan tradisional. Pemerintah pusat dan daerah bersepakat dalam pengembangan Teluk Awang sebagai pelabuhan perikanan terluar (outer ring fishing port) yang bertujuan untuk mengamankan potensi sumberdaya perikanan di daerah terluar dan berbatasan dengan perairan Negara tetangga (Srialdoko, 2019).

Secara geografis Teluk Awang terlindung dari gelombang yang datang dari Samudera Hindia. Kondisi tersebut memungkinkan dibangunnya pelabuhan perikanan untuk menfasilitasi peningkatan pemanfaatan sumberdaya perikanan di sekitar wilayah Teluk Awang. Sejalan dengan program yang dikembangkan oleh Pemerintah Pusat, Pemerintah Provinsi Nusa Tenggara Barat dan Pemerintah Kabupaten Lombok Tengah bersama-sama mengembangkan Teluk Awang menjadi sentra usaha perikanan dengan membangun pelabuhan perikanan yang dapat menampung kapal-kapal perikanan beroperasi di WPPNRI 573 dan 713. (DKP NTB, 2019)

Keberadaan Pelabuhan Perikanan Teluk Awang menjadi penting dalam menfasilitasi peningkatan pemanfaatan sumberdaya perikanan di sekitar wilayah Teluk Awang. Sehingga masyarakat sekitar tidak hanya bergantung pada perikanan Lobster. Potensi sumberdaya perikanan di Indonesia didapatkan dari sumberdaya perikanan tangkap, budidaya laut, perairan umum dan lainnya. Dalam rangka pengelolaan sumberdaya perikanan yang berkelanjutan. Pemerintah melalui Kementerian Kelautan dan Perikanan telah menerbitkan Keputusan Menteri Kelautan dan Perikanan RI No. 50/KEPMEN-KP/2017 tentang Estimasi Potensi, Jumlah Tangkapan yang diperbolehkan, dan Tingkat Pemanfaatan Sumberdaya Ikan di Wilayah Pengelolaan Perikanan Negara Republik Indonesia.

Sumberdaya Ikan (SDI) merupakan komponen utama dalam menentukan arah dan kebijakan pembangunan dan pengembangan di suatu kawasan pesisir. Kabupaten Lombok Tengah merupakan bagian dari WPPNRI 573 yang terletak di Samudera Hindia bagian selatan Jawa sampai bagian Selatan Nusa Tenggara, Laut Sawu dan Laut Timor (Aulia et al., 2017).

Hasil tangkapan sumberdaya Ikan yang dibongkar di Pelabuhan Perikanan Teluk Awang masih didominasi oleh ikan pelagis besar, ikan pelagis kecil dan demersal, selebihnya berupa ikan karang, lobster, udang, rajungan dan cumi-cumi (Srialdoko, 2019). Namun, minimnya informasi terkait potensi sumberdaya ikan di Pelabuhan Perikanan Teluk Awang 
menyebabkan tidak kuatnya argumen stakeholder dalam upaya pengelolaan perikanan di kawasan Teluk Awang.

Penelitian ini penting dilakukan untuk dapat memperoleh informasi terkait potensi sumberdaya ikan (SDI) selain lobster yang menjadi fokus perikanan di Teluk Awang terutama yang didaratkan di Pelabuhan Perikanan Teluk Awang, sehingga akan diperoleh strategi yang tepat dalam pengembangan perikanan berkelanjutan.

\section{BAHAN DAN METODE}

Penelitian ini akan dilakukan pada bulan Juni - November tahun 2020. Pengumpulan data pada penelitian dilakukan di Pelabuhan Perikanan (PP) Teluk Awang dan Desa Mertak, yaitu salah satu desa pesisir yang berada di Kecamatan Pujut, Kabupaten Lombok Tengah. Gambar 2 menunjukan lokasi Pelabuhan Perikanan dan Teluk Awang.

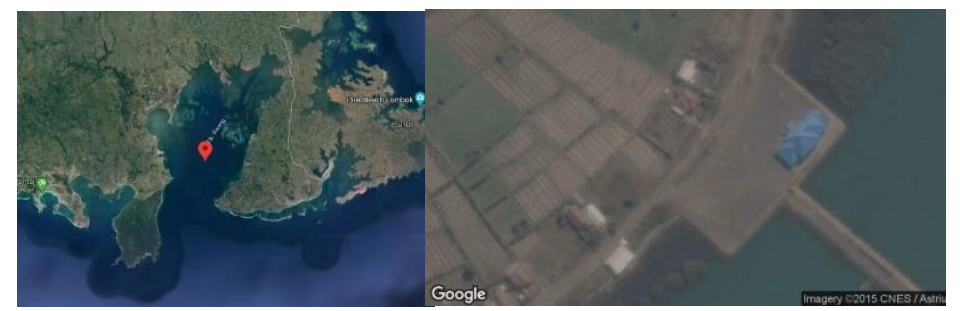

Gambar 1.Pelabuhan Perikanan (PP) Teluk Awang, Kabupaten Lombok Tengah

Data yang dikumpulkan pada penelitian ini berupa data sekunder dan data primer. Data sekunder yang dikumpulkan pada penelitian ini terdiri dari data statistik perikanan tangkap di Kabupaten Lombok Tengah, data pendaratan ikan di Pelabuhan Perikanan (PP) Teluk Awang, serta beberapa literatur lainnya. Data sekunder tersebut diperoleh dari Dinas Kelautan dan Perikanan Kabupaten Lombok Tengah, Kantor PP Teluk Awang, serta intansi terkait lainnya. Sementara itu, data primer pada penelitian ini berupa data jumlah nelayan, jenis dan jumlah alat tangkap, ukuran dan jenis kapal penangkap ikan, jenis dan jumlah ikan yang ditangkap dan didaratkan di PP Teluk Awang. Data primer pada penelitian ini dikumpulkan melalui in-depth interview dengan bantua kuesioner.

Penelitian ini dilakukan dalam beberapa tahapan penelitian, yaitu:

(1) Melakukan pengambilan data sekunder dan primer di PP Teluk Awang dan masyarakat nelayan Desa Mertak;

(2) Melakukan identifikasi potensi sumber daya ikan di PP Teluk Awang;

(3) melakukan penentuan pola pemanfaatan sumber daya ikan di PP Teluk Awang.

Analisis data yang digunakan untuk memetakan potensi sumber daya ikan di PP Teluk Awang adalah analisis statistik deskriptif. Analisis statistik deskriptif adalah statistik yang digunakan untuk menganalisis data dengan cara mendeskripsikan dan menggambarkan data yang telah terkumpul untuk kemudian menilai karakteristik dari sebuah data (Sholikhah, 2016). Pada penelitian ini, teknik analisis statistik deskriptif yang dilakukan dengan meliputi: 
a. Penyajian data dalam bentuk tabel atau distribusi frekuensi untuk mengidentifikasi jumlah nelayan, jumlah dan jenis alat tangkap, ukuran dan jumlah kapal penangkap ikan, jenis dan jumlah hasil tangkapan yang didaratkan, serta upaya penangkapan yang dilakukan oleh nelayan di PP Teluk Awang;

b. Penyajian data dalam bentuk visual berupa histogram, diagram batang, atau pie chart untuk dapat mengidentifikasi potensi sumber daya ikan di PP Teluk Awang. Selain itu, akan dilakukan penyajian data dalam bentuk pemetaan daerah penangkapan ikan oleh nelayan PP Teluk Awang;

c. Penghitungan ukuran tendensi sentral berupa rata-rata untuk mengidentifikasi produksi hasil tangkapan ikan yang didaratkan di PP Teluk Awang setiap bulannya;

d. Penghitungan trend untuk memetakan kegiatan penangkapan ikan setiap bulannya di PP Teluk Awang;

Analisis data yang dilakukan untuk mengidentifikasi pola pemanfaatan sumber daya ikan di Teluk Awang adalah analisis rich picture. Rich picture merupakan tool management scientific untuk menggambarkan hubungan antar elemen dari suatu sistem secara kompleks atau analisis situasi mengenai topik yang sedang dikaji (Checkland dan Poulter, 2006). Melalui analisis rich picture akan ditunjukan hubungan antar stakeholder pada kegiatan pemanfaatan sumber daya ikan di Teluk Awang, serta dapat diidentifikasi pola pemanfaatan sumber daya ikan yang dilakukan oleh nelayan di Teluk Awang.

\section{HASIL DAN PEMBAHASAN}

a) Potensi sumber daya ikan (SDI) yang didaratkan di Pelabuhan Perikanan Teluk Awang Hasil penelitan menunjukkan bahwa SDI yang di daratkan di PP Teluk Awang selama tahun 2018-2020 sebanyak 3.559.483 kg dengan rincian ikan Cakalang sebanyak 2.230.895 $\mathrm{kg}(62,67 \%)$, Layang $383.224 \mathrm{~kg}(10,77 \%)$, Tongkol $295.184 \mathrm{~kg}(8,29 \%)$, Lemadang $225.597 \mathrm{~kg}(6,34 \%)$, Tuna $192.911 \mathrm{~kg}(5,42 \%)$, Baby Tuna $137.944 \mathrm{~kg}(3,88 \%)$, Marlin $52.695 \mathrm{~kg}(1,48 \%)$ dan Ikan lainya $41.033 \mathrm{~kg}(1,15 \%)$ (Gambar 2 dan 3).

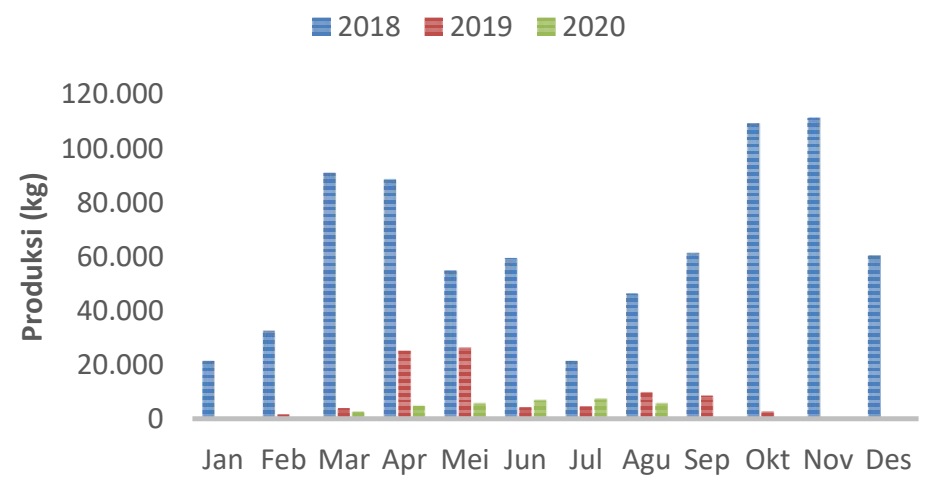

Gambar 2.Produksi Ikan yang didaratkan di PP. Teluk Awang, Kabupaten Lombok Tengah (*tahun 2020 hanya didata sampai bulan Agustus) 
Produksi SDI di PP Teluk Awang menunjukkan waktu optimal penangkapan terjadi pada bulan Oktober-November dan Maret-April dengan hasil tangkapan masih didominasi ikan pelagisbesar, ikan pelagis kecil dan demersal (Suman et al., 2016). Data ini menunjukkan bahwa PP Teluk Awang sangat potensial mengingat jumlah SDI yang didaratkan dari beberapa armada kapal yang berlabuh.

Produksi SDI yang didaratkan di PP Teluk Awang dari tahun 2018-2020 masih dominasi oleh Ikan Pelagis seperti cakalang sebanyak 2.230.895 kg (62,67\%) (Gambar 3). Jumlah tangkapan yang dominan disebabkan karena keberadaan armada kapal yang berlabuh di PP Teluk Awang mayoritas menggunakan alat tangkap pancing tonda, alat tangkap pancing tonda dikenal sangat efektif digunakan dalam menangkap Ikan Cakalang (Erfin, 2018).
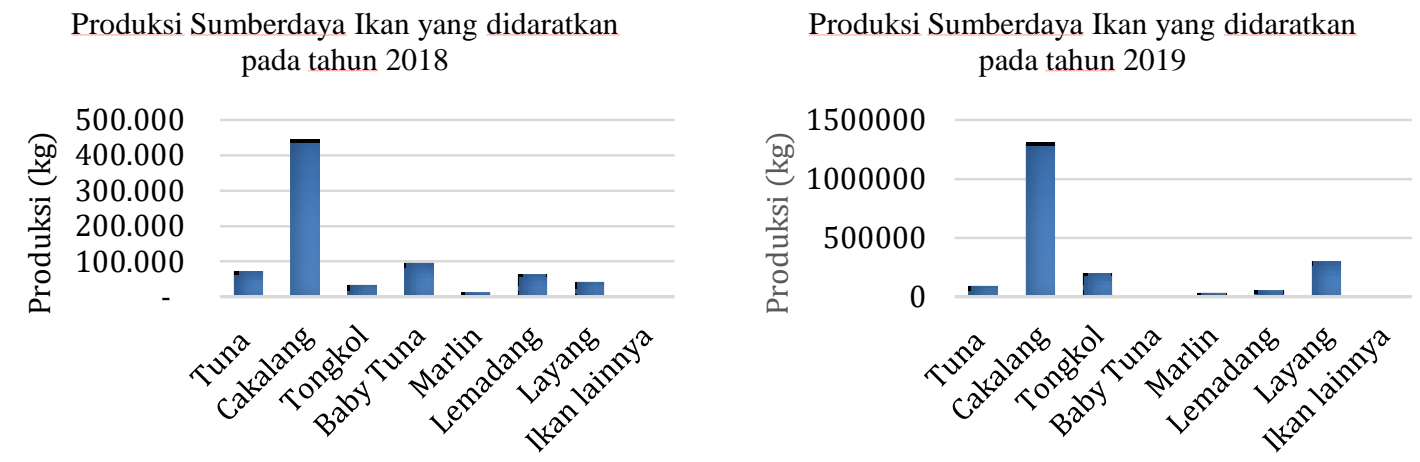

Produksi Sumberdaya Ikan yang didaratkan pada tahun 2020

Total Produksi Sumberdaya Ikan yang didaratkan pada tahun 2018-2020
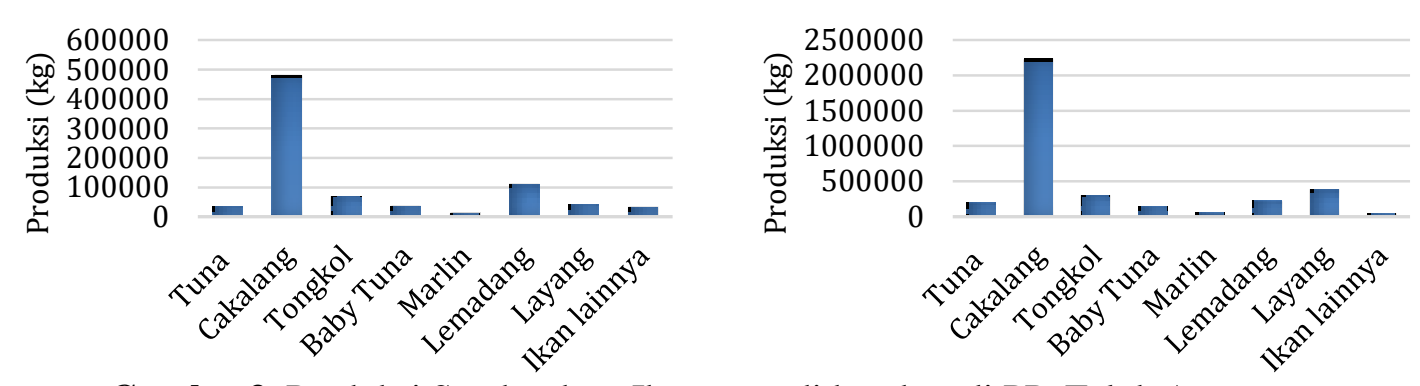

Gambar3. Produksi Sumberdaya Ikan yang didaratkan di PP. Teluk Awang pada tahun 2018-2020

b) Pola pemanfaatan sumber daya ikan (SDI) yang didaratkan di Pelabuhan Perikanan Teluk Awang

Armada penangkapan ikan yang mendaratkan ikan di Pelabuhan Perikanan Teluk Awang berasal dari masyarakat pesisir sekitar Teluk Awang dan dari luar Teluk Awang. Armada penangkapan ikan yang berasal dari Teluk Awang berukuran < 30 GT, sedangkan yang berasal dari luar Teluk Awang berukuran > 100 GT. Jenis alat tangkap yang digunakan oleh armada penangkapan ikan dari Teluk Awang adalah pancing tonda, sedangkan armada penangkapan ikan yang berasal dari luar Teluk Awang menggunakan alat tangkap pukat cincin. Secara umum, pancing tonda dioperasikan oleh kapal kayu atau fiberglass berukuran < 10 GT (Alimina et al., 2018), (Nurdin et al., 2016). Sementara itu, alat tangkap pukat cincin seringkali dioperasikan di laut lepas dengan kapal berukuran 131-149 GT (Jatmiko et al., 2020). 


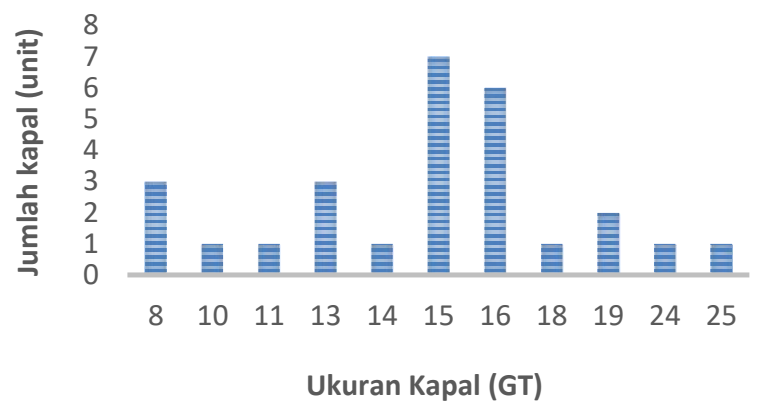

Gambar 4. Armada Penangkapan di PP. Teluk Awang, Kabupaten Lombok Tengah

Daerah penangkapan ikan untuk armada penangkapan pancing tonda dan pukat cincin yang mendaratkan ikan di Pelabuhan Perikanan Teluk Awang adalah di Wilayah Pengelolaan Perikanan (WPP) 573 dan 713. WPP 573 meliputi perairan Samudera Hindia sebelah Selatan Jawa hingga sebelah Selatan Nusa Tenggara, Laut Sawu, dan Laut Timor bagian Barat, sedangkan WPP 713 meliputi perairan Selat Makassar, Teluk Bone, Laut Flores, dan Laut Bali KKP, 2014). Adapun hasil tangkapan yang diperoleh di WPP 573 dan 713 oleh nelayan yang mendaratkan ikan di Pelabuhan Perikanan Teluk Awang diantaranya adalah ikan tuna, cakalang, tongkol, baby tuna, marlin, lemadang, layang, dan jenis ikan pelagis besar lainnya. WPP 573 dan 713 merupakan wilayah perairan yang memiliki potensi untuk sumber daya ikan pelagis besar karena sifat oseanik dari kedua WPP tersebut yang merupakan habitat utama ikan pelagis besar (Suman et al., 2016).

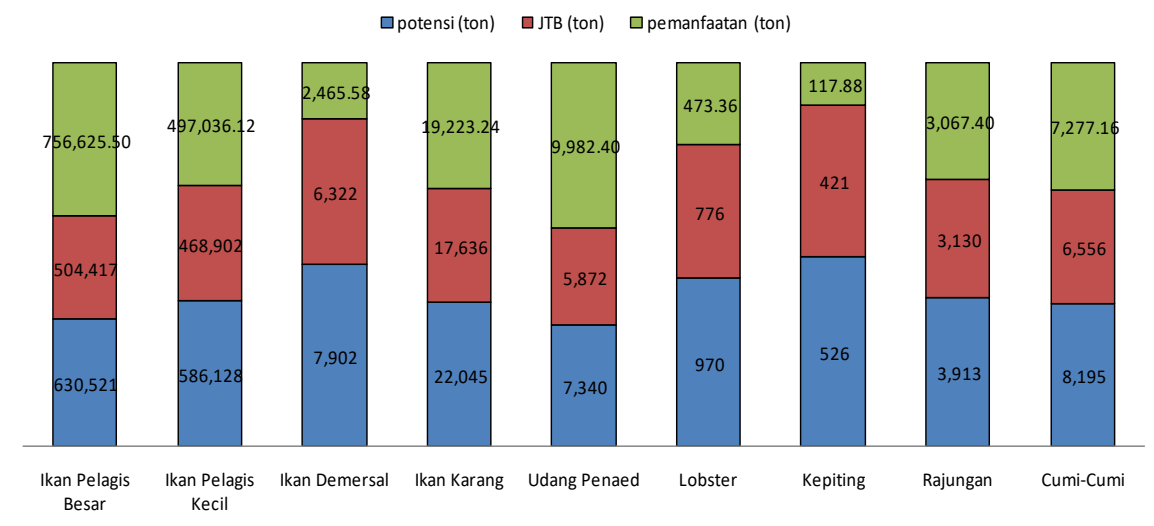

Gambar 5. Potensi dan pemanfaatan sumber daya ikan di WPP 573 tahun 2017

Hasil analisis terhadap data yang diperoleh selama penelitian menunjukan bahwa potensi kelompok ikan pelagis besar di WPP 573 adalah 630.521 ton pada tahun 2017, dengan jumlah tangkapan yang diperbolehkan adalah 504.417 ton. Namun, pemanfaatan kelompok ikan pelagis besar tersebut telah melebihi jumlah yang diperbolehkan, yaitu mencapai 756.625,50 ton. Sementara itu, kelompok ikan yang jumlah pemanfaatannya belum optimal di WPP 573 adalah kelompok ikan demersal dan kepiting. Hal serupa terjadi pula di WPP 713, yaitu terjadi pemanfaatan melebihi jumlah tangkapan yang diperbolehkan untuk kelompok ikan pelagis besar. Potensi kelompok ikan pelagis besar di WPP 713 adalah 208.414 ton, dengan jumlah tangkapan yang diperbolehkan adalah 166.731 ton. Sementara itu, pemanfaatan untuk kelompok ikan pelagis besar adalah 205.079,13 ton. Kelompok ikan 
yang pemanfaatannya belum optimal di WPP 713 adalah udang penaed dan rajungan (Srialdoko, 2019).

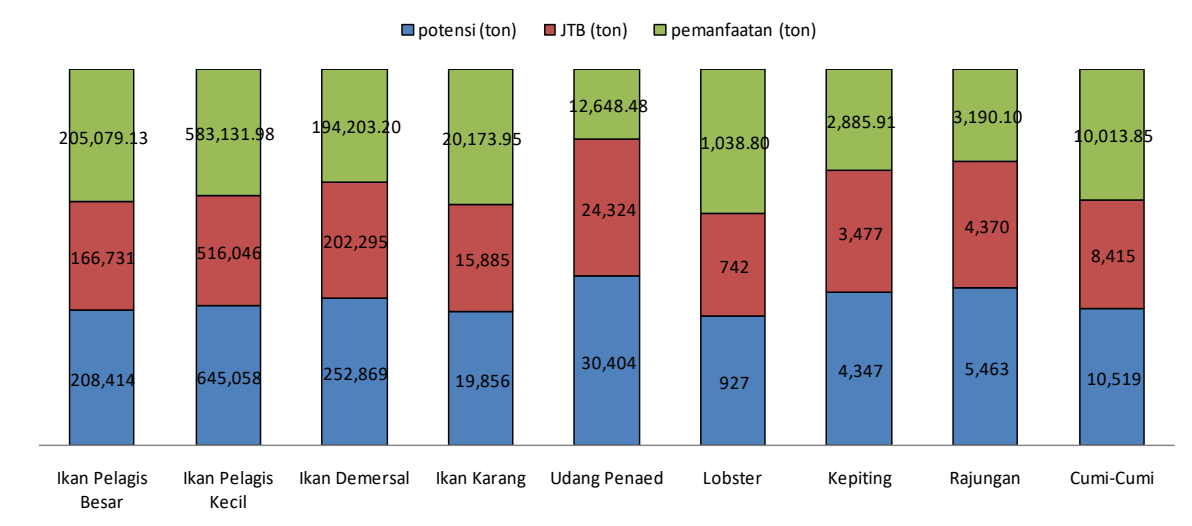

Gambar 6. Potensi dan pemanfaatan sumber daya ikan di WPP 713 tahun 2017

Ikan-ikan yang didaratkan di Pelabuhan Perikanan Teluk Awang kemudian didistribusikan ke perusahaan perikanan yang ada di Kabupaten Lombok Timur atau didistribusikan ke bandara untuk di pasarkan secara nasional atau ekspor. Media transportasi yang digunakan antara lain mobil box berpendingin atau mobil bak terbuka dengan box styrofoam yang berisi es curah. Secara umum, metode transportasi yang dilakukan oleh nelayan dan pengumpul ikan di Pelabuhan Perikanan Teluk Awang sudah sesuai dengan kaidah rantai dingin. Hal tersebut sangat penting karena penerapan rantai dingin sangat mempengaruhi mutu dari ikan hasil tangkapan (Prastyo et al., 2018). Gambar 7 menunjukan pola pemanfaatan sumber daya ikan yang didaratkan di Pelabuhan Perikanan Teluk Awang.

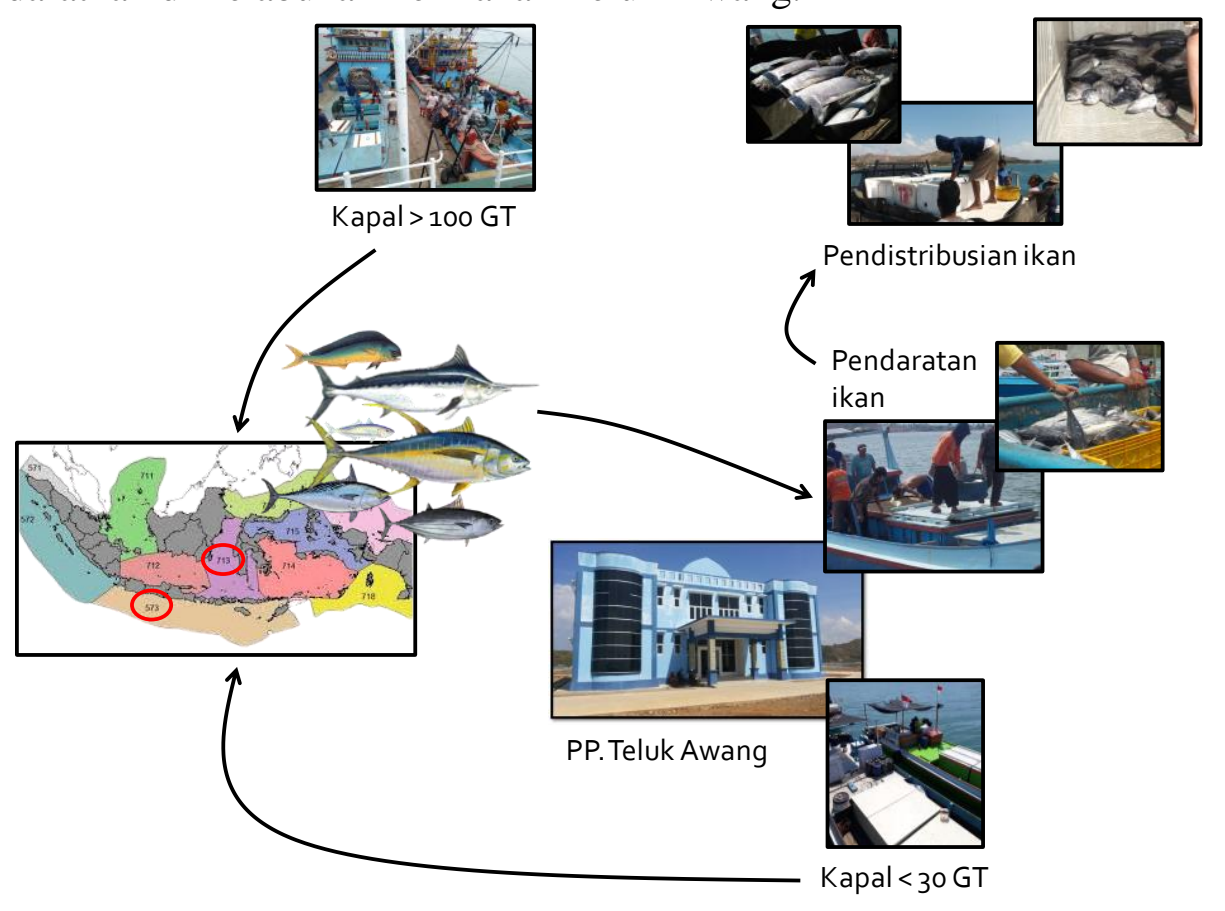

(Sumber gambar: google.com \& twitter.com/PPtelukawang?s=08, diolah) Gambar 7. Rich picture pemanfaatan sumber daya ikan yang didaratkan di Pelabuhan Perikanan Teluk Awang 


\section{KESIMPULAN}

Hasil tangkapan sumberdaya Ikan yang dibongkar di Pelabuhan Perikanan Teluk Awang masih didominasi oleh ikan pelagis dan demersal, seperti ikan Cakalang, Layang, Tongkol, Lemadang, Tuna, Baby Tuna, Marlin dan Ikan lainya. Sedangkan jumlah armada kapal yang terdata sebanyak 27 unit dengan ukuran 8-25 Gross Tonnage (GT) yang merupakan kapal dari nelayan lokal.Kapal yang mendaratkan ikan di PP. Teluk Awang terdiri dari klasifikasi kapal < 30 GT dan kapal > 30 GT, keduanya menangkap ikan di WP 573 dan 713. Kemudian pendistribusian ikan dilakukan melalui jalur darat untuk kemudian dibawa ke perusahaan pengumpul ikan atau langsung dibawa ke bandara untuk dipasarkan secara nasional maupun ekspor. Besarnya potensi ikan di WPP 573 dan 713 menjadikan PP. Teluk Awang menjadi lokasi pendaratan ikan yang potensial.

\section{Ucapan Terima Kasih}

Terimakasih kami sampaikan kepada Lembaga Penelitan dan Pengabdian Kepada Masyarakat Universitas Masyarakat atas bantuan dana penelitian dan Pengelola Pelabuhan Perikanan Teluk Awang beserta pihak-pihak yang terlibat dalam pengumpulan data selama penelitan

\section{DAFTAR PUSTAKA}

Aulia, D., Herry, B., \& D, W., 2017. Analisis Pengembangan Fasilitas Pembangunan yang Berwawasan Lingkungan (Ecoport) di Pelabuhan

Perikanan Nusantara (PPN) Pengambengan, Jembrana Bali. E Journal UNDIP, Download, Juli 2018.

Alimina, N., Wiryawan, B., Monintja, D. R., Nurani, T. W. \& Taurusman, A. A., 2016. Estimasi Tangkapan Per Unit Upaya Baku dan Proporsi Yuwana Pada Perikanan Tuna di Sulawesi Tenggara. Marine Fisheries, 7(1), 57-68.

Checkland P \& Poulter J. 2006. Learning for Action: A Short Definitive Account of Soft System Methodology and Its Use for Practitioners, Teachers and Students. Chichester: John Wiley.

[DKP] Dinas Kelautan dan Perikanan Provinsi NTB. 2019. Potensi Usaha dan Peluang Investasi Kelautan dan Perikanan. Direktorat Jenderal Penguatan Daya Saing Produk Kelautan dan Perikanan Kementerian Kelautan Perikanan Jakarta.

Erfin. 2018. Ikan Cakalang (Katsuwonus pelamis) dengan Menggunakan Pancing TondadiPerairan Teluk Maumere. MANGIFERA EDU: Jurnal Biologi and Pendidikan Biologi. 3(1), 16-25.

Jatmiko, I., Nugroho, S. C. \& Fahmi, Z., 2020. Karakteristik Perikanan Pukat Cincin Pelagis Besar di Perairan Samudera Hindia (WPPNRI 572 dan 573). Jurnal Penelitian Perikanan Indonesia, 26(1), 37-46.

[KKP] Kementerian Kelautan dan Perikanan, 2014. Peraturan Menteri Kelautan dan Perikanan Republik Indonesia Nomor 18/PERMEN-KP/2014 tentang Wilayah Pengelolaan Perikanan Negara Republik Indonesia. Jakarta: KKP.

Nurdin, E., Sondita, M. F. A., Yusfiandi, R. \& Baskoro, M., 2015. Produktivitas dan Musim Penangkapan Ikan Madidihang (Thunnus albacares Bonnaterre, 1788) Pada Perikanan Skala Kecil di Palabuhanratu, Jawa Barat. Jurnal Penelitian Perikanan Indonesia, 21(3), 147-154. 
Prastyo, A., Lubis, E. \& Purwangka, F., 2018. Pengaruh Transportasi Terhadap Mutu dan Harga Ikan dari Pelabuhan Perikanan Pantai Lempasing ke Daerah Konsumen. Albacore, 2(2), 209-219.

Sholikhah, A. 2016. Statistik deskripstif dalam penelitian kualitatif. Komunika. 10(2): 343362.

Srialdoko, J., 2019. Optimalisasi dan Pengembangan Pelabuhan Perikanan Teluk Awang di Lombok Tengah Nusa Tenggara Barat. Depok: Rajawali Pers.

Suman, A., Irianto, H. E., Satria, F. \& Amri, K., 2016. Potensi dan Tingkat Pemanfaatan Sumber Daya Ikan di Wilayah Pengelolaan Perikanan Negara Republik Indonesia (WPP NRI) Tahun 2015 serta Opsi Pengelolaannya. Jurnal Kebijakan Perikanan Indonesia, 8(2), 97-110. 